\title{
The state of Vitamin D in Iraqi Patients With Parkinson Disease
}

\author{
Aqeel Kareem. Hatem *, . Hayder Fadhil Lateef**
}

\section{ABSTRACT \\ Background: A role for vitamin $D$ deficiency in Parkinson disease (PD) has recently been suggested.}

Objective:: To estimate the state of vitamin $D$ in $P D$ with an age-matched healthy control.

Type of the study: A case control study.

Method: The study randomly comparison of plasma 25hydroxyvitamin $\mathrm{D}(25[\mathrm{OH}] \mathrm{D})$ concentrations of collected samples in a clinical neurology department ward / Baghdad teaching hospital / Medical City and Parkinson disease movement disorder clinic. Participants were registered into the study from October 2015 to October 2016. We was study serum vitamin $D$ level in 40 consecutive patients with Parkinson disease and 40 age-matched healthy controls after matching for age, sex, race, and geographic location. Occurrence of suboptimal vitamin D $25(\mathrm{OH})$ concentrations in Parkinson patients.

Results: Significantly, more patients with PD (62.5\%) had deficient vitamin $D$ than did controls $(27.5 \%)$. The mean
25(OH) D concentration in PD was (18.09) significantly lower than in the control (24.89)..

Conclusions: This study demonstrates a significantly lower vitamin $\mathrm{D}$ level in PD than healthy controls. These data support a possible role of vitamin $\mathrm{D}$ deficiency in PD.

Keywords: Vitamin D, Iraq, Parkinson.

\section{Al-Kindy College Medical Journal 2017: Vol. 13 No.1} Page: 137-141

*(MBCHB, FIBMS) consultant neurologist, chief of Parkinson disease and movement disorder clinic.

**(M.B.CH.B)Resident neurology- Baghdad teaching hospital/Iraq

Received 15 $5^{\text {th }}$ Feb 2017, accepted in final $30^{\text {th }}$ March 2017 Corresponding to: Aqeel Kareem.

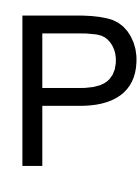

arkinson's disease (PD) is the second most common neurodegenerative disorder after Alzheimer disease, it an old term disorder of the central nervous system that mainly affects the motor system. ${ }^{[1]}$ The symptoms generally come on slowly over time. Early in the disease, the most obvious are shaking, rigidity, slowness of movement, and difficulty with walking. ${ }^{[1]}$ Thinking and behavioral problems may also occur. Dementia becomes common in the advanced stages of the disease. Depression and anxiety are also common occurring in more than a third of people with PD. ${ }^{[2]}$ other symptoms include sensory, sleep, and emotional problems. ${ }^{[1][2]}$ The main motor symptoms are collectively called "parkinsonism", or a "parkinsonian syndrome". ${ }^{[3]}$

Table (1) ${ }^{[4]}$

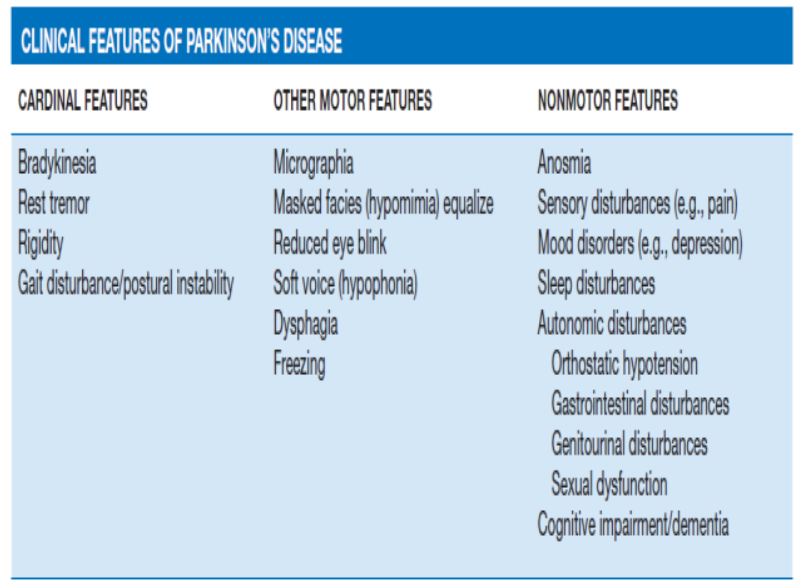

The cause of Parkinson's disease is generally unknown, but believed to involve both genetic and environmental factors. Those with a family member affected are more likely to get the disease themselves. ${ }^{[3]}$ There is also an increased risk in people exposed to certain pesticides and among those who have had prior head injuries while there is a reduced risk in tobacco smokers and those who drink coffee or tea. ${ }^{[3][5]}$ Vitamins D Important for maintaining many physiologic functions and vitamin $D$ deficiency is associated with increased risk of disease. Optimal balance, muscle strength, and innate immunity require adequate vitamin D levels. ${ }^{[6]}{ }^{[7]}{ }^{[8]}$ vitamin D deficiency is associated with increased risk for several types of cancer, as well as autoimmune and cardiovascular disorders. ${ }^{[8]}\left[{ }^{[9]}{ }^{[10]}{ }^{[11]}{ }^{[12]}\right.$ Vitamin D also regulates processes of immunity in multiple sclerosis, Parkinson disease (PD), and other neurodegenerative disorders, including neurotrophin, inducible nitric oxide synthase, glutathione and monoamine synthesis, and apoptosis. ${ }^{[13]}{ }^{[14]}$ The enzyme 25-hydroxyvitamin D-1_hydroxylase (1_-OHase) converts the storage 25hydroxyvitamin $\mathrm{D}(25[\mathrm{OH}] \mathrm{D})$ form to the biologically active vitamin D form,1,25-dihydroxyvitamin D. Both 1_OHase and vitamin D receptors (VDRs) are expressed in many extrarenal tissues, including muscle and brain. Given the high prevalence rates of vitamin D deficiency in such varied populations as elderly patients, chronically ill patients, healthy young adults and the widespread distribution of the VDRs and 1_-OHase in brain and muscle, ${ }^{[15][16]}$ optimal vitamin $D$ status may be important for preventing or treating neurodegenerative disorders. Active 1,25-dihydroxyvitamin D binds to VDRs and regulates approximately 200 genes involved in cell 
differentiation, proliferation, and apoptosis. ${ }^{[16]}$ In the brain, VDRs localize in the nucleus, whereas 1_- OHase is distributed throughout the cytosol. In particular, hippocampal and substantia nigra cells demonstrate high concentrations of VDRs and 1_- OHase. ${ }^{[15]}$ Finally the American geriatric society recommended vitamin D and calcium supplement to prevent fall in elderly .they recommended that 65 years old or older should consume 1000 I.U. vitamin D daily along with Calcium $1000-1200 \mathrm{mg}$ daily. ${ }^{[17]}$ one recent review of multiple study that vitamin D supplement in old people reduce fall by $20 \% .{ }^{[18]}$ both biological plausibility and epidemiology data indicate that vitamin $D$ level deficiency may contribute to the development of PD. . $^{[7]}$

Aim of study: To estimate the state of vitamin $D$ in Parkinson patients.

Methods: Design and Setting: Case control study was conducted in the neurology wards / Baghdad teaching hospital/ medical city and movement disorder clinic. The selected patients attended the medical center from October 2015 until October 2016 during their periodic visit seeking for medical advice concerning their sign and symptoms of Parkinson disease .

Study population:This study performed on 40 patients (24 male and 16 female, with mean age 59.225, 23 urban and 17 rural) diagnosed with Parkinson disease according to bank criteria. Who attended neurology wards / Baghdad teaching hospital/ medical city and movement disorder clinic under supervision of consultant neurologist.Their selection follows the following criteria:

Inclusion criteria: Idiopathic Parkinson disease diagnosis by UK Parkinson's disease society brain bank clinical diagnostic criteria. ${ }^{[19]}$ Patients having a weight range from $(45-85) \mathrm{kg}$. Patients are aged more than 40 years old.

\section{UK Parkinson's Disease Society Brain Bank Clinical Diagnostic Criteria ${ }^{[19]}$}

Step 1: Establish the presence of bradykinesia (slowness of initiation of voluntary movement with reduced speed and amplitude of movements and/or the loss or decrease of automatic movements) plus at least one of the following:Rigidity, $4 \mathrm{Y} 6 \mathrm{~Hz}$ resting tremor, Postural instability (not otherwise explained by primary visual, vestibular, cerebellar, or proprioceptive dysfunction)

Step 2: Evaluate for exclusionary criteria for the diagnosis of Parkinson disease. The absence of a history of: Repeated strokes with a stepwise progression of Parkinsonism, Repeated head injury, Definite encephalitis, Neuroleptic treatment at onset of symptoms, More than one affected relative (although this exclusion criterion is no longer commonly used), Any period of sustained remission, Oculogyric crises
Early severe autonomic involvement, Early severe dementia with disturbances of memory, language, and praxis

- $\quad$ 1-Methyl-4-phenyl-1,2,3,6-tetrahydropyridine (MPTP) exposure

- OR a finding of:

- Strictly unilateral features after 3 years

- Negative response to large doses of levodopa (if malabsorption is excluded)

- Supranuclear gaze palsy

- Cerebellar signs

- Babinski sign

- Cerebral tumor or communicating hydrocephalus on neuroimaging

Step 3: Establish the presence of three or more of the supportive criteria for the diagnosis of Parkinson disease

- Unilateral onset

- Resting tremor present

- Progressive disorder

- Persistent asymmetry with symptoms worse on the side of onset

- Clear and definite response (70 to $100 \%$ improvement on Unified Parkinson's Disease Rating Scale) to levodopa

- $\quad$ Severe levodopa-induced chorea

- Levodopa response for 5 years or more

- Clinical course of 10 years or more

The disease severity can assess by Stages of Hoehn and Yahr Scalea ${ }^{[20]}$

1.0 Unilateral involvement only

1.5 Unilateral and axial involvement

2.0 Bilateral involvement without impairment of balance

2.5 Mild bilateral disease with recovery on pull test

3.0 Mild to moderate bilateral disease; some postural instability; physically independent

4.0 Severe disability; still able to walk or stand unassisted

5.0 Wheelchair dependent or bedridden unless aided

\section{Exclusion criteria:}

1. Atypical parkinsonian syndromes (e.g. multiple system atrophy, progressive supranuclear palsy, corticobasal syndrome).

2. Secondary Parkinsonism (drug-induced, vascular, structural, infectious, immunologic, toxic, traumatic, metabolic). 
3. Chronic renal failure.

4. Patients have other diseases like DM, cardiovascular and CNS diseases.

5. Patients take vitamins supplements.

6. Patients with abnormal parathyroid hormone.

All patients were screened according to a strict protocol consisting of a full neurological examination, standardized blood tests and electrolytes included serum Calcium and phosphate and parathyroid hormone, magnetic Resonance imaging of the brain and cardiac analysis including standard 12-lead electrocardiography in all patients and serum vitamin D3. Serum levels of $25(\mathrm{OH}) \mathrm{D}$ were stratified into normal ( $\geq 30 \mathrm{ng} / \mathrm{ml}$ ), insufficient ( $\geq 20$ to $<30 \mathrm{ng} / \mathrm{ml}$ ) and deficient $(<20 \mathrm{ng} / \mathrm{ml})$. ${ }^{[21]}$

\section{Statistical Analysis:}

Data were analyzed by means of statistical package for social sciences (SPSS) software programs. Values were expressed as mean $+\backslash$ - SD. a comparison of continuous variables was performed by unpaired two-tailed Student's t test. A level of $\mathrm{P}<.05$ (two-sided testing) was considered statistically significant.

Result: We was study 40 patients in-group I (PD patients), the Mean age of the patients was 59.225 \pm 5.968 years and 40 healthy patient in-group II (control) with mean age $59.750 \pm 5.674$.

In the group I (PD patients), there was 24 Male and 16 female, with mean BMI 21.958 and residency distributed in to 23 urban and 17 rural. In the group II (control), there was 23 male and 17 female, with mean BMI 23.277 and residency distributed in to 28 urban and 12 rural (Table 2).

This study, show there is no significant difference between the two groups regarding the age, sex, BMI, or residency (Table 2 ).

We found that is a significant relationship between the two groups regarding the vitamin $D$ level. In-group I (PD patients) the mean vitamin $D$ level was $18.09 \pm 8.56$ and $24.89 \pm 9.10$ in-group II ( $p$ value 0.001 ). As shown in (table 3).

It is obvious that in Parkinson disease patients (group I), there was $15(37.5 \%)$ patients with normal VDL and $25(62.5 \%)$ had deficient VDL, while in healthy control (group II), there was 29(67.5\%) normal VDL and 11 (27.5\%) deficient VDL.

The frequency of serum $(\mathrm{OH})$ vitamin $D$ deficiency among Parkinson disease patients show: $8(20 \%)$ patients with mild deficiency (15-19 ng/dl), 10 (25\%) patients with moderate deficiency $(10-14 \mathrm{ng} / \mathrm{dl})$ and 7 $(17.5 \%)$ patients with severe deficiency $(<10 \mathrm{ng} / \mathrm{dl})$.

There is no significant different in vitamin $D$ level between male and female in Parkinson patients (group I) with $p$ value 0.716 (table 4 ).

\begin{tabular}{|c|c|c|c|c|c|}
\hline \multicolumn{2}{|c|}{ GROUP } & $\mathrm{N}$ & Mean & Std. & $P$ \\
\hline \multirow[t]{2}{*}{ AGE } & I & 40 & 59.225 & 5.968 & \multirow[t]{2}{*}{0.685} \\
\hline & II & 40 & 59.750 & 5.674 & \\
\hline \multirow[t]{2}{*}{ SEX } & I & 40 & $24 / 16$ & 0.4961 & \multirow[t]{2}{*}{0.812} \\
\hline & II & 40 & $23 / 17$ & 0.5006 & \\
\hline \multirow[t]{2}{*}{ BMI } & I & 40 & 21.958 & 3.282 & \multirow[t]{2}{*}{0.062} \\
\hline & II & 40 & 23.277 & 4.533 & \\
\hline \multirow[t]{2}{*}{ RSE } & I & 40 & $23 / 17$ & 0.5006 & \multirow[t]{2}{*}{0.281} \\
\hline & II & 40 & $28 / 12$ & 0.4641 & \\
\hline
\end{tabular}

\begin{tabular}{|c|c|c|c|c|c|c|}
\hline \multicolumn{7}{|c|}{ Table 3. vitamin D level } \\
\hline GROUP & N & Mea & $\begin{array}{c}\text { Std. } \\
\text { Deviatio } \\
\text { G }\end{array}$ & $\begin{array}{c}\text { Percentag } \\
\text { e of VDL } \\
\text { deficient }\end{array}$ & P \\
\hline VITD & I & 4 & 18.0 & 8.56 & $62.5 \%$ & 0.00 \\
& & 0 & 9 & & & 1 \\
\hline & II & 4 & 24.8 & 9.10 & $27.5 \%$ & \\
\hline & 0 & 9 & & & \\
\hline
\end{tabular}

STATE OF V. D IN PD AND CONTROL

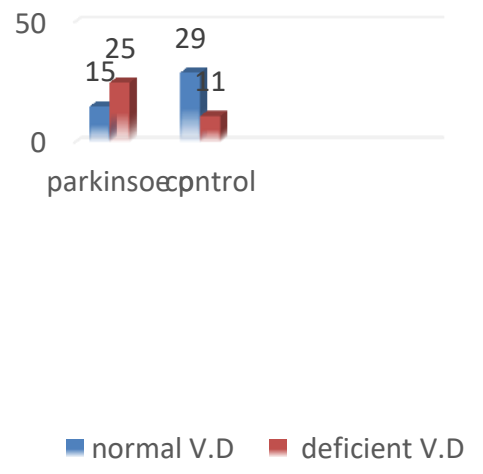

Figure 1 state of VDL in PD and control 


\section{frequency of vitamin D deficiency in parkinson}

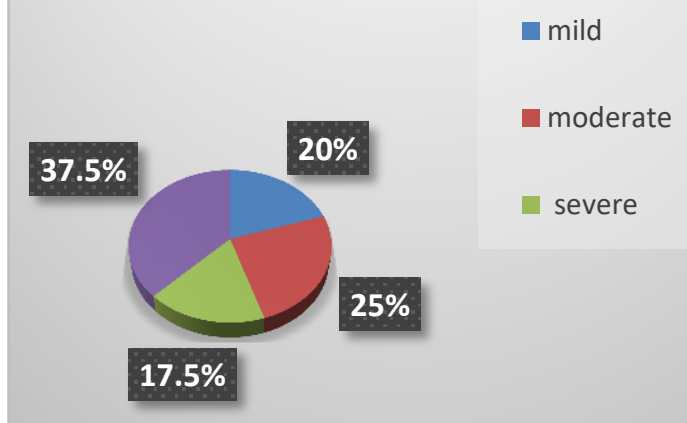

Figure 2 frequency of VDL in PD according to severity of deficiency.

\begin{tabular}{|c|c|c|c|c|c|}
\hline \multicolumn{3}{|c|}{ Table 4. relation VDL between male and female in PD } \\
\hline \multicolumn{2}{|c|}{ GROUP I } & $\mathrm{N}$ & Mean & $\begin{array}{c}\text { Std. } \\
\text { Deviation }\end{array}$ & $\mathrm{P}$ \\
\hline \multirow{2}{*}{ VITD } & Male & 24 & 17.68 & 8.80 & 0.716 \\
\cline { 2 - 5 } & Female & 16 & 18.70 & 8.42 & \\
\hline
\end{tabular}

Discussion:This is the first study investigate vitamin $D$ level in Iraqi patients with Parkinson disease compare to the age matched healthy control. Vitamin D deficiency is an important condition in the elderly. The Prevalence of neurodegenerative disease is also higher in these patients. [22][ 23] The results of this study show that (62.5\%) Parkinson patients enrolled in the study having deficient vitamin $D$ level with mean $\pm S D$ was significantly lower $(18.09 \pm 8.56 \mathrm{ng} / \mathrm{ml})$ compared to (27.5\%) of healthy controls without Parkinson disease with mean \pm SD was significantly higher $(24.89 \pm 9.10 \mathrm{ng} / \mathrm{ml})$ in healthy controls $(P=<0.001)$.

However, the finding of low levels of $25(\mathrm{OH}) \mathrm{D}$ in individuals with Parkinson could be explained by the insufficient synthesis in the skin as PD patients experience mobility problems more frequently than control healthy persons this make a PD patient less likely to get sun exposure and account for the higher prevalence of vitamin $D$ deficiency. In addition, inadequate intake or absorption of vitamin $D$, low seafood intake, limited outdoor activities, and decreased awareness about fortification with vitamin $D$ may affect vitamin D status in these groups. ${ }^{[24]}$ An alternative aspect was ruled out such as age, sex and BMI, the impacts of these factors on vitamin D status, were no significant. Several lines of evidence point to possible role of vitamin $D$ in $P D$, Studies of brain tissue show that receptors for vitamin $D$ are widely distributed in brain are affected by PD suggested an important role in normal function. ${ }^{[15][25]}$ This result agree with study done in 2008 at Emory University School of Medicine establish both patients with Parkinson disease and Alzheimer disease had significantly lower vitamin D level. ${ }^{[26]}$ Also, approve in Study by Dr. Yoshihiro Sato, Department of Neurology, Kurume University Medical Center that found a High prevalence of vitamin D deficiency and reduced bone mass in Parkinson's disease. ${ }^{[27]}$ Furthermore this study is compatible with study done In Iran, at 2013 study include Eighty-three patients with Parkinson's disease (PD) were recruited using simple non-random sampling. 25-hydroxyvitamin D [25(OH) D3] was measured by Electro chemilumine scence immunoassay (ECLIA) The mean 25(OH) D3 concentration was lower in the PD population than in the normal group. ${ }^{[28]}$

Accumulating data have provided evidence that $1 \alpha, 25$ dihydroxyvitamin D3 [1,25-(OH)2D3] is involved in brain function. Thus, the nuclear receptor for 1,25$(\mathrm{OH}) 2 \mathrm{D} 3$ has been localized in neurons and glial cells. The reported biological effects of $1,25-(\mathrm{OH}) 2 \mathrm{D} 3$ in the nervous system include the biosynthesis of neurotrophic factors and at least one enzyme involved in neurotransmitter synthesis. 1,25- $(\mathrm{OH}) 2 \mathrm{D} 3$ can also inhibit the synthesis of inducible nitric oxide synthase and increase glutathione levels, suggesting a role for the hormone in brain detoxification pathways. Neuroprotective and immunomodulatory effects of this hormone have been described in several experimental models, indicating the potential value of $1,25-(\mathrm{OH}) 2 \mathrm{D} 3$ and pharmacological analogs in neurodegenerative and neuroimmune diseases. ${ }^{[29]}$ The vitamin $D$ receptors found in high concentration in substetia nigra, the region of brain affected by PD .vitamin $D$ exhibit a neuroprotective effect through antioxidant mechanism, neuronal calcium regulation, immunomodulation lead to enhance nerve conduction and detoxification mechanism. ${ }^{[25]}$ According to gender in current study, there is no significant difference between male and female with Parkinson patients in VDL.This finding reported by Isfahan Neurosciences Research Center study 109 patient of PD at 2013 the result High prevalence of $25 \mathrm{OHD}$ insufficiency but no sex difference in VDL with Mean \pm SD levels of $250 H D$ were $28.5 \pm 1.4$ and $27.1 \pm 1.5$, for males and females, respectively. ${ }^{[30]}$

\section{References:}

1. De Lau LM, Breteler MM. Epidemiology of Parkinson's disease. Lancet Neurol. 2006;5(6):525-535.

2. Svein bjornsdottir $\mathrm{S}$. The clinical symptoms of Parkinson's disease. Journal of Neurochemistry. 2016 Oct 1;139(S1):318-324.

3. Kalia LV, Kalia SK, Lang AE. Disease-modifying strategies for Parkinson's disease. Movement Disorders. 2015 Sep 15;30(11):1442-1450. 
4. C. Warren Olanow, Anthony H.V. Schapira: edition, Elsevier Inc, 2013.CH.30: P 334.

5. Campdelacreu J. Parkinson's disease and Alzheimer disease: environmental risk factors. Neurología. 2014 Dec 31;29(9):541-549.

6. Holick MF. Vitamin D deficiency. New England Journal of Medicine. 2007 Jul 19;357(3):266-281.

7. Nagpal S, Rathnachalam R. Noncalcemic actions of vitamin D receptor ligands. Endocrine reviews. 2005 Aug 1;26(5):662-687.

8. Bischoff-Ferrari HA, Dietrich T, Orav EJ, et al. Higher 25-hydroxyvitamin D concentrations are associated with better lower-extremity function in both active and inactive persons aged $\geq 60 \mathrm{y}$. The American journal of clinical nutrition. 2004 Sep 1;80(3):752-758.

9. Grant WB, Garland CF, Gorham ED. An estimate of cancer mortality rate reductions in Europe and the US with 1,000 IU of oral vitamin D per day. InCancer Prevention 2007 :pp. 225-234.

10. Gorham ED, Garland CF, Grant WB, et al. Optimal vitamin $D$ status for colorectal cancer prevention: a quantitative meta analysis. American journal of preventive medicine. 2007 Mar 31;32(3):210-216.

11. Garland CF, Garland FC, Gorham ED, et al. The role of vitamin $D$ in cancer prevention. American journal of public health. 2006 Feb;96(2):252-261.

12. Zittermann $A$. Vitamin $D$ and disease prevention with special reference to cardiovascular disease. Progress in biophysics and molecular biology. 2006 Sep 30;92(1):39-48.

13. Garcion E, Wion-Barbot N, Montero-Menei CN, et al. New clues about vitamin $D$ functions in the nervous system. Trends in Endocrinology \& Metabolism. 2002 Apr 1;13(3):100-105.

14. Baksi SN, Hughes MJ. Chronic vitamin D deficiency in the weanling rat alters catecholamine metabolism in the cortex. Brain research. 1982 Jun 24;242(2):387-390.

15. Eyles DW, Smith S, Kinobe R, et al. Distribution of the vitamin $D$ receptor and 1a-hydroxylase in human brain. Journal of chemical neuroanatomy. 2005 Jan 31;29(1):21-30.

16. Mukhtar $\mathrm{O}$, Jackson $\mathrm{SH}$. Drug therapies in older adults (part 1). Clinical Medicine. 2015 Feb 1;15(1):47-53.

17. Holick MF. Vitamin D: importance in the prevention of cancers, type 1 diabetes, heart disease, and osteoporosis. The American journal of clinical nutrition. 2004 Mar 1;79(3):362-371.

18. Newmark HL, Newmark J. Vitamin $D$ and Parkinson's disease-a hypothesis. Movement Disorders. 2007 Mar 15;22(4):461-468.
19. Daniel SE, Lees AJ. Parkinson's Disease Society Brain Bank, London: overview and research. Journal of neural transmission. Supplementum. 1992 Dec;39:165-172.

20. Goetz CG, Poewe W, Rascol O, et al. Movement Disorder Society Task Force report on the Hoehn and Yahr staging scale: status and recommendations the Movement Disorder Society Task Force on rating scales for Parkinson's disease. Movement disorders. 2004 Sep 1;19(9):1020-1028.

21. Del Valle HB, Yaktine AL, Taylor CL, et al. Dietary reference intakes for calcium and vitamin $D$. National Academies Press; 2011 Apr 30.

22. Holick MF, Chen TC. Vitamin D deficiency: a worldwide problem with health consequences. The American journal of clinical nutrition. $2008 \mathrm{Apr}$ 1;87(4):1080S-1086S

23. Lawson DE, Paul AA, Black $A E$, et al. Relative contributions of diet and sunlight to vitamin $D$ state in the elderly. Br Med J. 1979 Aug 4;2(6185):303305.

24. Shults CW, Oakes D, Kieburtz K, et al. Effects of coenzyme Q10 in early Parkinson disease: evidence of slowing of the functional decline. Archives of neurology. 2002 Oct 1;59(10):15411550.

25. Ishihara LS, Cheesbrough A, Brayne C, Schrag A. Estimated life expectancy of Parkinson's patients compared with the UK population. Journal of Neurology, Neurosurgery \& Psychiatry. 2007 Dec 1;78(12):1304-1309.

26. Evatt ML, DeLong MR, Khazai N, et al. Prevalence of vitamin $D$ insufficiency in patients with Parkinson disease and Alzheimer disease. Archives of neurology. 2008 Oct 13;65(10):1348-1352.

27. Sato $Y$, Asoh T, Oizumi K. High prevalence of vitamin $D$ deficiency and reduced bone mass in elderly women with Alzheimer's disease. Bone. 1998 Dec 31;23(6):555-557.

28. Moghaddasi M, Mamarabadi M, Aghaii M. Serum 25-hydroxyvitamin D3 concentration in Iranian patients with Parkinson's disease. Iranian journal of neurology. 2013;12(2):56.

29. de Abreu DF, Eyles D, Feron F. Vitamin D, a neuroimmunomodulator: implications for neurodegenerative and autoimmune diseases. Psychoneuroendocrinology. 2009 Dec 31;34:S265277.

30. Chitsaz A, Maracy M, Basiri K, et al. 25Hydroxyvitamin D and severity of Parkinson's disease. International journal of endocrinology. 2013 Jul 17;2013. 